\title{
Designing a camel: a new BMA logo
}

\author{
RAY FISHWICK
}

\begin{abstract}
"How would you like to design," they said "a new logo and type style for our stationery and publications? We have all these people within the BMA doing their own thing and the printed material that comes out of here takes some believing." (I believed: I'd seen some of it.)

"Actually," they said, "we approached a couple of West End design consultancies to quote for a complete corporate image but the BMA treasurer's hair turned white when he saw the cost. How about your doing us a budget version ? Bit by bit, that is, a gradual process."

"We have a roundel version of the BMA coat of arms, of course," they continued, "and many of us are very attached to it, but it doesn't reduce well-looks like a button when small, in fact-and with the increasing range of material we put out we find it doesn't lend itself well to all our needs. It tends to fill in, particularly if we reverse it out of a background colour."

"However, we'd like to retain the roundel for special occasions, ceremonial and suchlike."

"And I'd like to retain Eric Gill's symbol design for special uses, too," said the editor, hedging his bets quickly, "invitations to social functions and things like that, you understand."

"And we're building up our print department downstairs, so any type you use must be available to them."

And that, basically, was the brief.
\end{abstract}
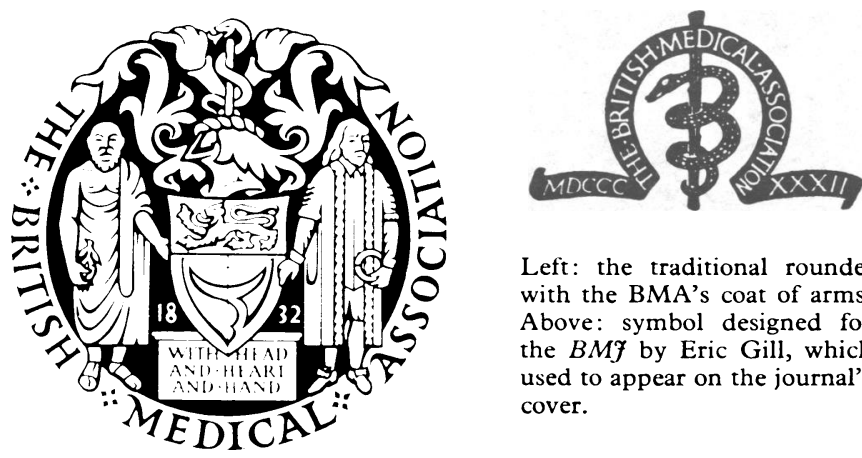

Left: the traditional roundel with the BMA's coat of arms. Above: symbol designed for the $B M f$ by Eric Gill, which used to appear on the journal's cover.

Back in the studio, clean layout pad on the drawing board, I examine the roundel for clues and look for somewhere to start.

The roundel contains something for everyone. A rod and serpent (of healing) over crossed torches (of learning) tops a knight's helmet swathed in a formalised twist of material. All this atop a shield containing a Royal Lion and a medieval lady's sleeve (maunche-from the coat of arms of the founder of the BMA, Sir Charles Hastings). Supporting the shield are, to the left, the figure of Harvey, the founder of modern British medicine holding a circle indicating his discovery of the circulation, and to the right, Hippocrates, the founder of medicine and medical ethics, holding in his right hand the apple of health. Also included are the date 1832, when the BMA was founded, and the words "With head and heart and hand." The whole design is ringed with the words "The British Medical Association."

So far as I know there is no original artwork to be found, and every time a printer needs to reproduce it he has to search desperately for some previous example which has been printed well enough for further use as an original.

Lloyd Fishwick Associates Ltd, Stutton, Suffolk IP9 2SS RAY FISHWICK, artist and designer
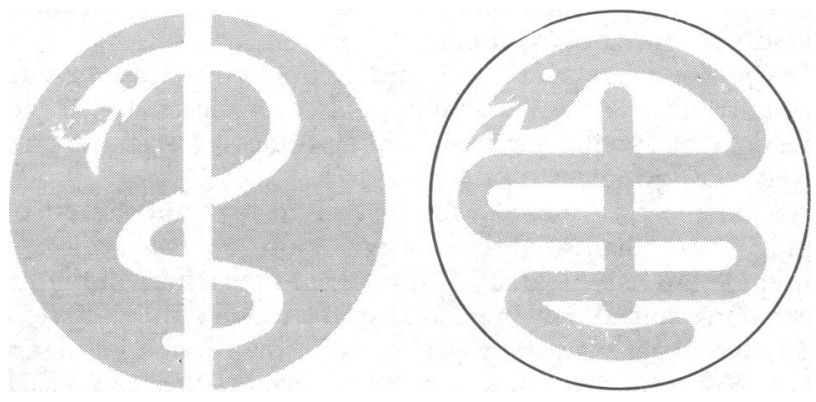

Two early ideas.

\section{First sketches}

In my first sketches I tried to achieve popularity by including several of the principal ingredients, but this approach became hopelessly convoluted and overcrowded. I then produced an emblem reminiscent of a vintage automobile badge. There was no doubt that the lion and maunche had to go. Some years ago when I started designing for the BMA I began with the impression that they were such a conservative bunch that the sure road to success was to produce designs of such a traditional nature that no one would notice that anything had changed. That assessment has been modified, and here was clearly a case for a more direct approach. We had to be ruthless and home in on the essential serpent and staff-the ancient caduceus emblem associated with healing since the earliest days of medical history.

First encounters with the snake were not promising. Attempts at a formal design produced an electric hotplate, an $S$ bend, a dollar sign, a slowworm. I leafed through reference books on corporate images and logos looking for inspiration. Scribbles, ideas, overlaid amendments to previous drawings littered the studio.

Of one fact I was convinced: the most successful current logos which fulfil their intended role most efficiently are just those which are the most modern, succinct, and uncluttered.

Eventually a design evolved and I mounted the sketches carefully on board showing the symbol drawn large, in various versions, and its application in a small size to ranges of stationery and covers of books and reports. At 12 noon on the appointed day I was summoned into the corporate presence of the finance and general purposes committee. A brief introduction from $\mathrm{Dr}$ John Marks, a benevolent smile from the chairman, and then I was invited to do my bit. Mumbling that anything I wished to say to the committee had already been adequately covered by Dr Marks, I opened my case and held aloft for all to see my considered solution to the BMA logo problem.

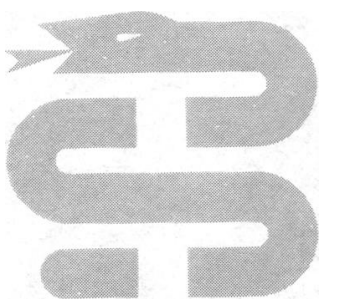


There was a long moment's stunned silence, and then a voice on my left said "Ugh!" Not a good start, I thought. A lively discussion ensued.

A head count showed a majority against the design for various reasons, including anxiety about the openness of a snake motif to sarcasm, especially from hostile journalists. Someone else just didn't like snakes.

I broke an unwritten designers' rule and showed various sketches leading up to the final design and rejected in the evolutionary process. (The client invariably latches on to an earlier rejected version which you hate.)

"If you don't like snakes," I said, "could you please give me some guidance as to a starting point." Armed with several suggestions of varying shades of unhelpfulness, I was invited to go away and try again.

I sat on the train home with my no go logo and licked my wounds, more than slightly pensive. Not too easy, this: my inspired design had to satisfy a large committee whose individual expectations ranged from a raised fist to a touch of heraldry only slightly less regal than the royal coat of arms framed in a laurel wreath. Not only that; they didn't like snakes! Where was I to make a new start-crossed scalpels? Stethoscopes rampant?

The BMA had barely finished celebrating 150 years of hallowed tradition and here they were ready to cast aside any link with the traditional symbol of their profession.

There was no doubt: it really did have to be the snake.

I decided to concentrate on two alternatives. The first was to work on a symbol, as requested, derived from the façade of BMA House, and the second was to continue developing the modernised caduceus symbol incorporating various amendments in answer to specific criticisms. By the time our subcommittee met again I was able to produce several BMA House designs (which I hoped would be rejected out of hand) and a new superimproved version of the snake.

"We like it," they said. "It's very aggressive," said the editor. I thought the head section needed further consideration. Back to the drawing board for a number of variations to reduce its "snakosity."

In the few weeks' interval before the next subcommittee meeting the evolving snake was kept pinned to the studio wall in the hope that seeing it afresh each day I would catch it unawares and the ultimate solution would reveal itself. It was like an eye test at the optician's: is this an improvement or was it better like that?

I substituted a round eye for the slanted eye, changed the forked tongue, reduced its size, removed it from the mouth, removed the mouth, removed the head.

Of the three designs submitted for the subcommittee's consideration, the most abstract was rejected, as was a non-aggressive version, promptly dubbed "snoopy snake." A third version was accepted.

The finance and general purposes committee meeting was a few days later. The plan was to display the rejected snake symbol during an introductory speech outlining again the history of this project and the practical need for a new logo. We would then produce the various unsuccessful designs based on the façade of BMA House. Finally, we would produce the new design (see logos by the title), avoiding shock by presenting it
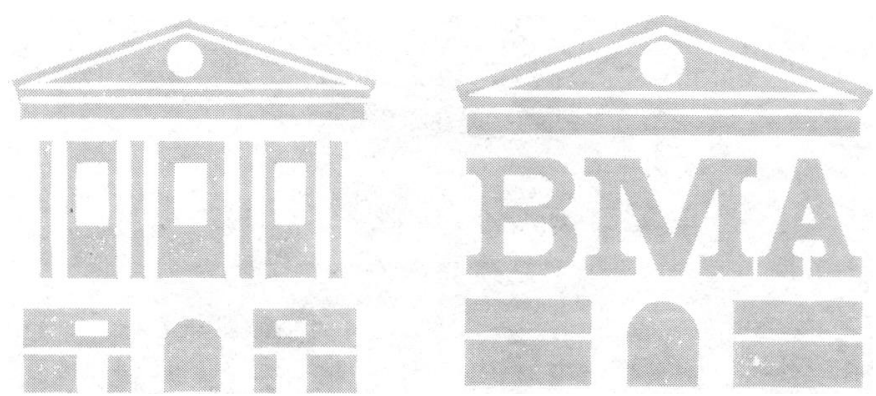
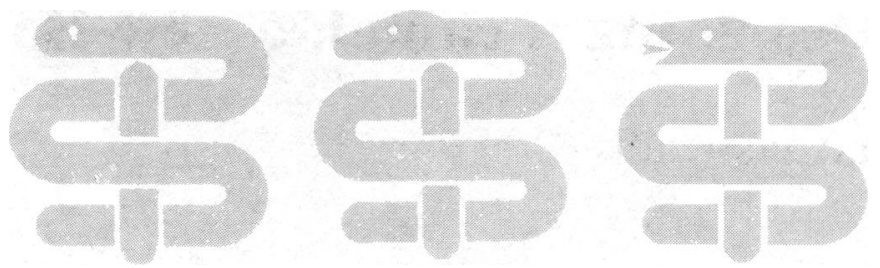

The version of the snake logo finally accepted is that on the right.

on a small scale in a dozen or so sample wallets of letterheadings, envelopes, and compliments slips. Only then would the large drawn version be displayed.

Surprisingly, a large majority among the committee announced themselves in favour. The principal objector stopped short of personal assault but launched a scathing attack against the brash Madison Avenue image which I was attempting to impose on this august and venerable institution.

Without delay the chairman conducted a head count among those eligible to vote on this issue and announced a majority in favour of the new logo. To get anything through this committee with a seven to two majority was a major achievement, he assured me. I learnt later of some active lobbying that had been going on in the days before the meeting.

Back in rural Suffolk I shooed the chickens off the road again. The next night, with much cursing in the moonlight, I struggled to drag a renegade cow back through the decaying boundaries of our patch, tugging grimly at her collar while unravelling a barbed wire fence with the other hand.

Home it may be; Madison Avenue, hardly.

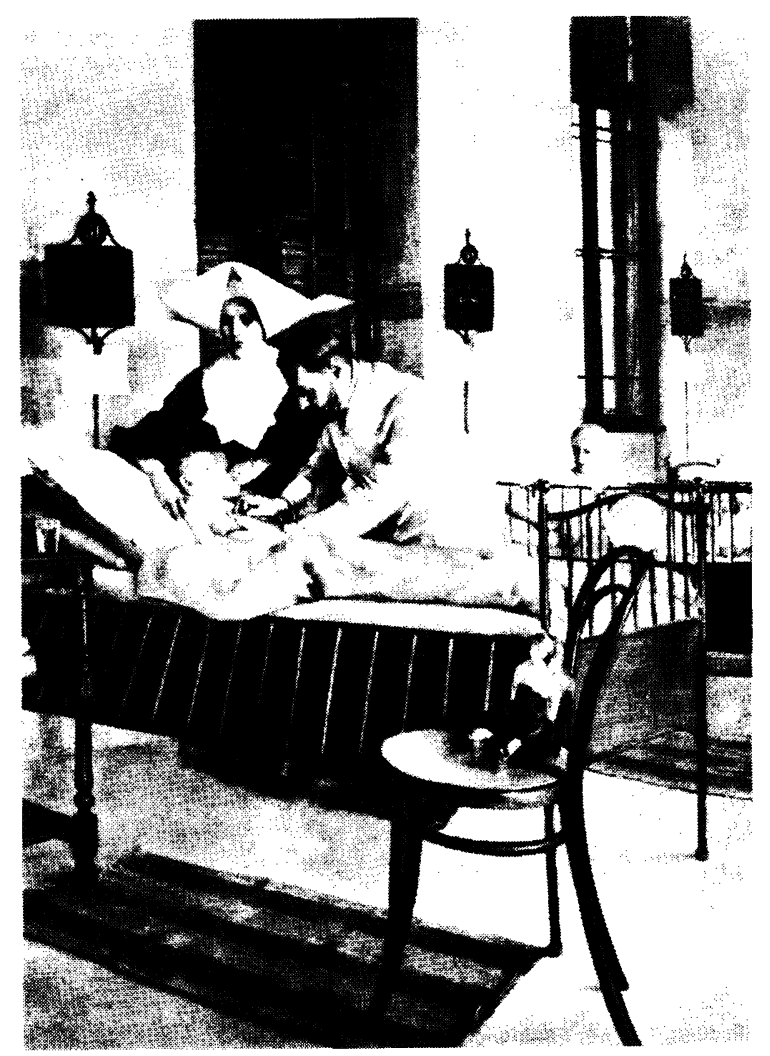

Im Kinderspital. Heliogravure after Imre Knopp, 1892. 